scopy, and H. V. Neher (California Institute of Technology) spoke about cosmic rays at high altitudes and latitudes. The only contribution on theoretical physics was by J. Schwinger, who dealt with some formal developments in quantum mechanics. The complete list of invited and other papers, together with abstracts, is given in the minutes of the meeting ${ }^{2}$.

The programme ${ }^{3}$ of the meeting of the American Association of Physics Teachers consisted of thirtysix contributed papers, two invited papers and two round-table discussions on "Physics beyond General Physics for Non-Physics Majors" and "Undergraduate Laboratory Teaching". The former discussion was mainly concerned with physics requirements for engineering students; there was general agreement that instruction in physics should not be transferred from departments of plysics to those of engineering, and the question of the use of the 'slug' and the general topic of units was deferred to the next annual meeting. At the business meeting of the Association on January 24, it was agreed to confer honorary membership on R. Pohl, professor of physics in the University of Göttingen, and on J. H. Keenan, professor of mechanical engineering in the Massachusetts Institute of Technology, and to award citations to H. K. Hughes, for his painstaking work as chairman of the Committee of Letter Symbols; E. C. Kemble, as chairman of the Coulomb Law Committee ; 'T. H. Osgood, as editor of the American Journal of Physics; R. R. Palmer, as programme chairman of the Association's meetings in 1952 and 1953 ; K. Lark-Horovitz, for his teaching activities ; and to $M$. W. White, for his successful efforts on behalf of the Association. The following were elected to hold office for 1953: President, P. E. Klopsteg; President-elect, M. White; Treasurer, F. W. Sears; and Secretary, R. F. Paton.

${ }^{1}$ Published in Amer. J. Phys., 21, 369 (1953).

${ }^{2}$ Published in Phys. Rev., 90, 333 (1953).

s Published in full in Amer. J. Phys., 21, 401 (1953).

\section{OROGRAPHIC CIRRUS CLOUDS}

T has long been recognized that the forced ascent of air over mountains can produce cloud. Only in the past twenty years has it been realized that thin clouds $10,000 \mathrm{ft}$. or more above the mountains and with no cloud beneath them may owe their existence to the presence of the mountains. Such clouds are not formed by the direct lifting of the lower air up to cloud-level but in the ascending currents of a system of waves which can be produced by the mountain in somewhat the same way that a rock on a river bed produces waves downstream. The wind and temperature structures of the air have to fulfil certain conditions, as Dr. R. S. Scorer, of the Department of Meteorology, Imperial College of Science and Technology, London, has shown. The favourable conditions are an increase with height of both wind-speed and of the temperature lapse-rate. An inversion of temperature in the lower layers of the air followed by a rapid fall of temperature higher up is a favourable arrangement; but a steep fall of temperature with height low down, such as occurs on sunny afternoons, is unfavourable. When the temperature structure is right for waves to form, there must be sufficient water vapour at some height if a cloud is to appear in the ascending currents of the waves at that height.

The Moazagotl clouds which form at $12,000 \mathrm{ft}$. or more above the Riesengebirge in Germany were found by sailplane pilots to be forming in ascending currents of air and seem to have been the first really high clouds to be recognized as definitely orographic in origin.

Now Mr. F. H. Ludlam, a colleague of Dr. Scorer, claims in the October 1952 issues of Weather and the Quarterly Journal of the Royal Meteorological Society that some of the cirrus cloud seen over England at heights as great as $20,000 \mathrm{ft}$. or more is produced in orographic waves. $\mathrm{He}$ believes orographic cirrus forms as water particles at a temperature of about $-40^{\circ}$ C. The drops soon freeze, and are carried downwind as a trail of ice crystals. Making observetions from Dunstable, Bedfordshire, of the azimuth and elevation of the initial points of some cirrus trails and taking the height from the $-40^{\circ} \mathrm{C}$.-level in the Meteorological Office upper-air temperature readings, he has been able to relate these initial points to prominent hills such as the Black Mountains, the Long Mynd, Cleeve Hill and the Peak, some of them more than a hundred miles from Dunstable. Sometimes a number of cirrus trails, all at the same height, could be seen streaming each from above the hill responsible for it. A further height check made with good results was a comparison of the movement of details of the trails with the official upper wind observations. In support of his idea he points out that aircraft pilots have observed up and down currents of several metres per second at 10,000 $30,000 \mathrm{ft}$. over the low English hills. Further, the cirrus formation diminishes in the afternoon in accordance with Dr. Scorer's theory of wave formation.

Mr. Ludlam's ingenious and picturesque ideas are not yet accepted by all meteorologists. However, they promise to add a new pleasure to cloud observing-finding the hill over which a cirrus trail begins.

\section{HETEROGENEITY OF DEOXYRIBONUCLEIC ACIDS}

\section{By Dr. GEOFFREY L. BROWN and M. WATSON \\ Medical Research Council Biophysics Research Unit, Wheatstone Physics Laboratory, King's College, London, W.C.2}

$T$

$\mathrm{HE}$ current belief that deoxyribonucleic acids are intimately concerned in the maintenance and transmission of genetic specificity, for which there is a considerable amount of evidence, leads to the suggestion that preparations of this material may possibly consist of a large number of molecular species differing very slightly from each other in some respect. Chargaff and his collaborators ${ }^{1}$ and Wyatt ${ }^{2}$ have analysed many deoxyribonucleic preparations with regard to their content of purine and pyrimidine bases, and have found that preparations isolated from the same species have a constant composition, whereas the compositions of preparations from different species vary considerably. There are then three evident ways in which specific differences can be carried by the deoxyribonucleic acid of one species. Either it contains a number of molecules 